J. Dairy Sci. 99:4097-4097

http://dx.doi.org/10.3168/jds.2016-99-5-4097

(C) American Dairy Science Association ${ }^{\circledR}, 2016$.

\title{
Corrigendum to "Casein infusion rate influences feed intake differently depending on metabolizable protein balance in dairy cows: A multilevel meta-analysis" (J. Dairy Sci. 99:2748-2761)
}

\section{R. Martineau, D. R. Ouellet, E. Kebreab, and H. Lapierre}

In the caption for Figure 2 (page 2757), the lines were incorrectly identified. The negative MP balance is shown by the solid bold line and solid circles, whereas the positive MP balance is shown by the dashed line and open circles. The corrected caption (correction in bold) and figure are shown below.

The authors regret the error.

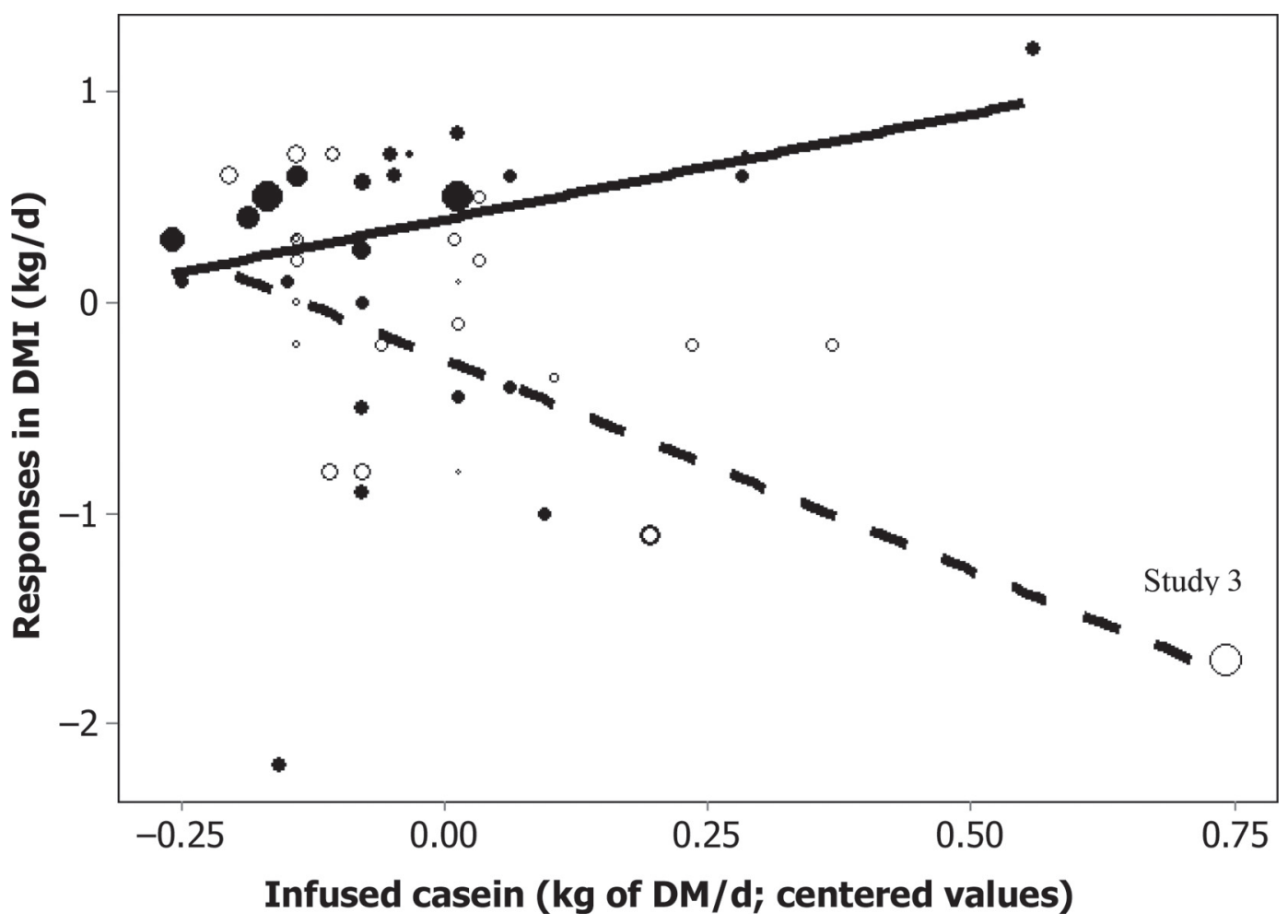

Figure 2. Graph showing the influence of the $\mathrm{CN}$ infusion rate $(\mathrm{kg}$ of $\mathrm{DM} / \mathrm{d}$; centered values) on responses in DMI (kg/d) as a function of MP balance (meta-regression 2 in Table 4). Negative MP balance $=$ straight bold line and closed circles; positive MP balance $=$ dashed bold line and open circles. Each response in DMI is drawn proportional to its statistical weight (i.e., the inverse of the corresponding SE). Study 35 (refer to Table 1) is not shown for scaling reasons.

\section{REFERENCES}

Martineau, R., D. R. Ouellet, E. Kebreab, and H. Lapierre. 2016. Casein infusion rate influences feed intake differently depending on metabolizable protein balance in dairy cows: A multilevel meta-analysis. J. Dairy Sci. 99(4):2748-2761. 